\title{
Surgical Management of Root Canal Overfill Without Paresthesia: Case Report
}

\author{
Akcay C*, Koltuk M and Koseoglu GB \\ Department of Oral and Maxillofacial Surgery, Istanbul University, Turkey
}

Submission: September 27, 2016; Published: December 13, 2017

*Corresponding author: Akcay C, Department of Oral and Maxillofacial Surgery, Istanbul University, Istanbul, Turkey, Email: cgrakcay@gmail.com

Abstract

Background: Overfill materials can cause undesirable complications such asneuro-sensorial problems.

Case Description: Report describes a case of surgical approach to extruded sealent material in a first left molar which causes neighter anestesian or pain.

Conclusions: Extruded material extracted immediately in order to prevent any neuro sensorial complication

Keywords: Endodontic overfill; Surgery; Endodontic extrusion; Paresthesia

\section{Introduction}

Theultimategoal of the endodontic treatment is hermeticobturation. As a complication following the root canal treatment, sealent material can leak from the root canal into bone oral so into the inferior alveolar canal. The present report decribes a case of surgical approach to extruded sealent material after endodontic treatment in a first left molar which causes neighter anestesian or pain.

\section{Case Report}

A male, 35 year-old patient directed to Department of Oral and Maxillofacial Surgery for examination and treatment of overfilled root in his first-left molar. Overfill material was noticed in radiographic examination immediately after the endodontic treatment, only complaint that patient made is fracture at the treated tooth and related tooth has a huge amalgam filling which has weaken and caused it to fracture.

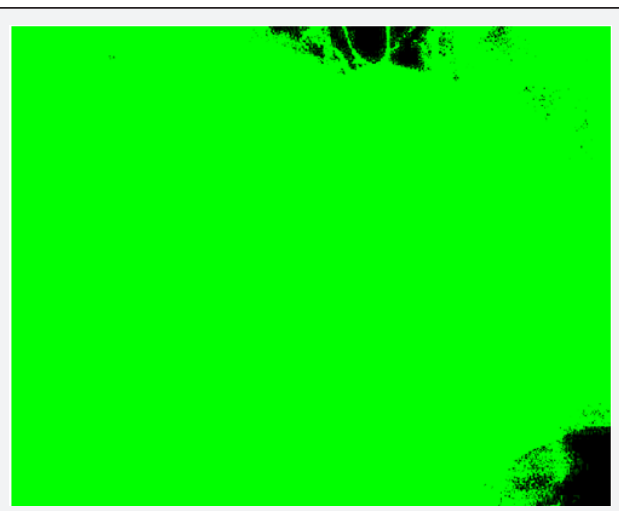

Figure 1: Preoperative panoramic radiography: Sealant material and inferior alveolar canal seem associated.
According to panoramic radiography (Figure 1), it was thought that the lesion might be related with alveolar canal. According to CBCT, overfill material seems not to be associated with the canal, so it was decided to operate patient.

Patient was operated under local anaesthesia. After extraction of first-left molar, mucoperiosteal flap elevated and a lateral bone window created on the buccal side of the lesion. Overfilled material was curetted away and the cavity washed with saline solution (Figure 2). The adjacent tooth which was in very poor condition was also removed during surgery. Operation site was closed primarily with 3-0 silk sutures, Non-steroid antiinflammatory (NSAI) drugs and amoxicillin were prescribed. In control radiography (Figure 3), it was seen that all of the excessive material (Figure 4) was removed successfully. In tenth day control session, patient shows no signs of paresthesia, anaesthesia or other complication.

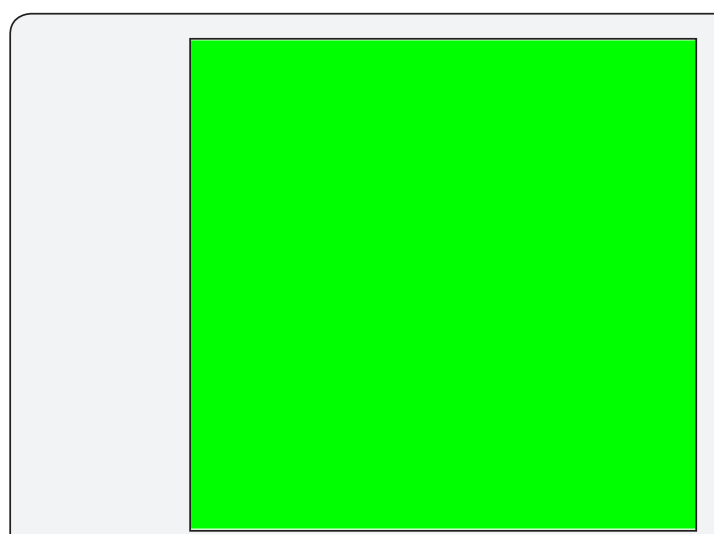

Figure 2: Intra-operative photo showing operation area after extraction and curettage. 

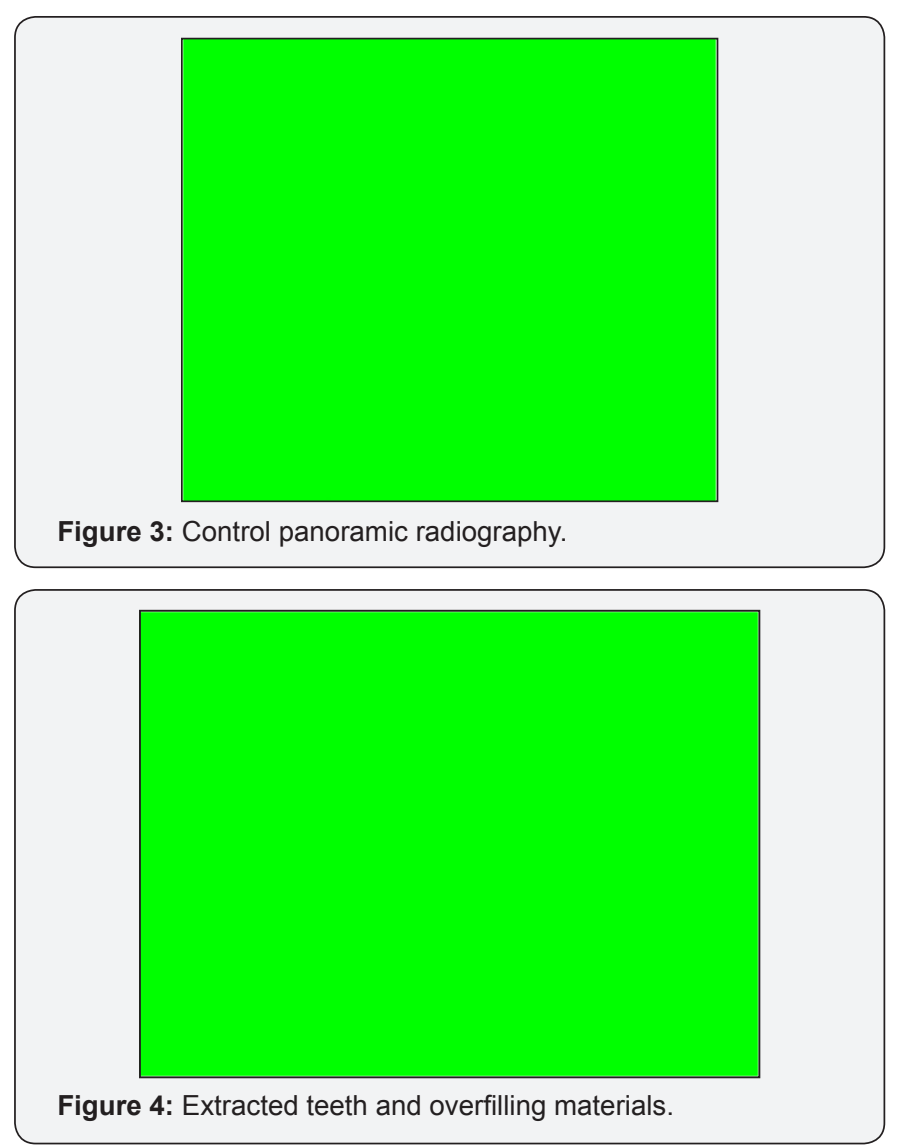

\section{Discussion}

Overfilled canal was described as the one that was well filled in three dimensions but exhibited surplus filling material past the apex [1]. Even though spontaneous resorption has been described for some materials, early surgical removal is suggested. According to Gonza'lez-Martın et al. [2] use of an electronic apex detector together with a radiograph taken with the files in position will help to avoid overextension or perforation [2].
Poveda et al. [3] and Tilotta et al. [4] presented case reports about mental nerve and inferior alveolar nerve paresthesia associated with endodontic paste. In our case, as it seen in magnetic resonance images, excessive paste material is not related with alveolar canal. As a result patient feel no discomfort despite extruded material amount is quite large. Endodontic treatment complications such as overfill must be diagnosed well and managed as soon as possible in order to avoid any sensory disturbances which can be occurred because of mechanical pressure or chemical toxic reaction of overfilled paste. Surgical management of the inferior alveolar nerve is effective in the treatment of nerve injuries caused by endodontic extrusion of endodontic paste according to Byun et al. [5]. In our case patient feel no paresthesia or anaesthesia, extruded material extracted immediately in order to prevent any neuro sensorial complication.

\section{Reference}

1. Gluskin AH (2009) Anatomy of an overfill: a reflection. Endodontic Topics 16(1): 64-81.

2. Maribel GM, Daniel TL, Jose' L (2010) Inferior Alveolar Nerve Paresthesia after Overfilling of Endodontic Sealer into the Mandibular Canal. Case Report/Clinical Techniques 36(8): 1419-1421.

3. Poveda R, Bagán JV, Fernández JM, Sanchis JM (2006) Mental nerve paresthesia associated with endodontic paste within the mandibular canal: report of a case. Oral Surg Oral Med Oral Pathol Oral Radiol Endod 102(5): e46-e49.

4. Tilotta-YF, Millot S, El Haddioui A, Bravetti P, Gaudy JF (2006) Labiomandibular paresthesia caused by endodontic treatment:an anatomic and clinical study. Oral Surg Oral Med Oral Pathol Oral Radiol Endod 102(4): e47-e59.

5. Byun HS, Kim SS, Chung HJ, Lim HK, Hei WH, et al. (2015) Surgical management of damaged inferior alveolar nerve caused by endodontic overfilling of calcium hydroxide paste. International Endodontic Journal 49(11): 1020-1029.

\section{Your next submission with Juniper Publishers} will reach you the below assets

- Quality Editorial service

- Swift Peer Review

- Reprints availability

- E-prints Service

- Manuscript Podcast for convenient understanding

- Global attainment for your research

- Manuscript accessibility in different formats

( Pdf, E-pub, Full Text, Audio)

- Unceasing customer service

Track the below URL for one-step submission https://juniperpublishers.com/online-submission.php 